\title{
Inclusão de pessoas com deficiência através das lutas e artes marciais
}

\author{
Rafael Carvalho da Silva MOCARZEL* \\ Universidade do Porto (Portugal) \\ Recepción: 25/09/2016; Aceptación: 28/12/2016; Publicación: 28/12/2016.
}

ORIGINAL PAPER

\section{Resumo}

Este artigo investigou como as lutas / artes marciais foram adaptadas para a inclusão das pessoas com deficiência, tanto em âmbito social quanto reabilitativo e desportivo-competitivo. A análise foi feita inicialmente de maneira global e posteriormente foi convertida maior atenção à realidade brasileira. Fez-se uso da revisão narrativa de literatura. Foram consideradas as seguintes lutas / artes marciais: esgrima, judo, karate, kung-fu, boxe, taekwondo e capoeira. Concluiu-se que as lutas / artes marciais podem colaborar ao combate à exclusão social, contribuir com a promoção da saúde, estética e lazer, sendo possível ainda descobrir novos talentos no desporto adaptado. São necessários mais estudos sobre o tema.

Palavras-chave: deficiência; lutas; artes marciais; desportos de combate; inclusão.

\section{Inclusión de personas con discapacidad a través de las luchas y deportes de combate \\ Resumen}

En este artículo se propone investigar cómo se adaptaron las luchas / artes marciales para la inclusión de las personas con discapacidad, tanto en el ámbito social, como para la rehabilitación y el deporte competitivo. El análisis se realizó a nivel global en primer lugar, para prestar atención seguidamente a la realidad brasileña, utilizando para ello una revisión narrativa de la literatura. Se estudiaron las siguientes luchas / artes marciales: esgrima, judo, karate, kung fu, boxeo, taekwondo y capoeira. Se concluyó que las luchas / artes marciales pueden contribuir a la lucha contra la exclusión social, contribuyendo a la promoción de la salud, la estética y el ocio, y también se pueden descubrir nuevos talentos para el deporte adaptado. Son necesarios más estudios sobre el tema.

Palabras clave: discapacidad; luchas; artes marciales; deportes de combate; inclusión.

\section{Inclusion of people with disabilities through fights and martial arts}

\section{Abstract}

This article aimed at investigating how the fights / martial arts were adapted for inclusion of people with disabilities in the social sphere as well as for rehabilitation and sports-competition. The analysis was initially made at the global level and later specific attention was paid to the Brazilian reality, through a narrative review of literature. The following fights / martial arts were considered: fencing, judo, karate, kung fu, boxing, taekwondo and capoeira. It was concluded that the fights / martial arts can contribute to combating social exclusion, contributing to the promotion of health, beauty and leisure and new talents in parasports can be discovered too. Further studies on the subject are needed.

Keywords: disability; fights; martial arts; combat sports; inclusion.

\section{Introdução}

É preciso se ter alguma prudência quando se fala de integração e/ou inserção pelo desporto. Por vezes, ouve-se falar, sobretudo através dos meios de comunicação social e alguns políticos, que o desporto integra "por natureza". Apoiando-se nas pretendidas virtudes educativas, cívicas e de cidadania, inalteráveis no tempo, o desporto terá uma capacidade natural de integração e de inserção. Esta visão é redutora e continua a ser uma construção ideológica (Gasparini, 2005). No entanto, tal ideologia continua, reforça-se, ajudada pelos efeitos de algumas atualidades simbólicas ou de midiatização, em percursos isolados ou excecionais. Aparentemente, existem resultados tangíveis sobre a integração e/ou inserção pelo desporto (Gasparini, 2005). No entanto, certos autores avançam que o poder de integração através do desporto e das atividades físicas é real.

Para além do futebol (Lever, 1983), outras modalidades desportivas são conclamadas para ajudar neste processo de integração e/ou inserção. Pode-se destacar o basquetebol de rua, que teve

*E-mail: professormocarzel@gmail.com 
grande sucesso nos anos de 1990 (sobretudo na França), num contexto de forte receptividade social, favorecido pela midiatização das equipas norte-americanas. Também a dança hip-hop responde muitas vezes às motivações de meninas e jovens moças (Garcia, 2005). Ou ainda as lutas / artes marciais (LAM) que permitem incentivar o gosto do confronto num quadro de regras restrito e, desta forma, a "eufemização" da violência (Dunning \& Elias, 1994; Rosa, 2016).

As atividades físicas e práticas esportivas, incluindo-se neste estudo as LAM, começaram a sinalizar a necessidade de uma transformação didático-pedagógica do esporte como é enfatizado por Kunz (1994) e Beltrame e Sampaio (2015). Pode-se dizer que um dos pontos mais necessitados junto ao desenvolvimento educacional é a abrangência cada vez maior dos aspectos pedagógicos e socioculturais inclusivos, atendendo assim de forma mais adequada às crianças, idosos e pessoas com deficiência (PD). Traz-se a discussão de que possivelmente o público de PD seja historicamente o mais excluído nesse universo cultural de forma macrossociológica (Marsiglia, 2016). Mais de um bilhão de pessoas sofrem com alguma deficiência no mundo todo (Organização Mundial da Saúde [OMS], 2016). No Brasil há quase trinta milhões de deficientes (Pena, et al., 2014). Pontua-se que atividades físicas e práticas esportivas não só podem mas devem ser utilizadas na colaboração da inserção sociocultural de todos e para todos (Seron, Arruda, \& Greguol, 2015). Tais princípios são embasados e sustentados por atuais e importantes documentos de abrangência internacional, como a Carta Europeia do Desporto (Conselho da Europa, 1992) e o Manifesto Mundial da Educação Física (Fédération Internationale d'Éducation Physique [FIEP], 2000). Já Andrade e Almeida (2012) são categóricos quando afirmam que as políticas públicas brasileiras tratam do tema de maneira superficial. Indo além sobre o caso brasileiro, Azevedo e Barros (2004, p.77) alertam através de seu estudo que verificou:

(...) o fato de o esporte não possuir uma identificação específica na estrutura governamental compromete qualquer política pública esportiva, com reflexos ainda mais expressivos nas iniciativas direcionadas aos indivíduos portadores de deficiência, cujas representatividades e influência política - pela própria situação da deficiência - são muito inferiores às de outros grupos esportivos organizados.

Analisando sob outro prisma, Seron et al. (2015) dizem que ainda é necessário pesquisar e descobrir mais sobre os motivos da maioria das PD não conseguirem integrar ou mesmo praticar atividades físicas de maneira regular em seu cotidiano. Dessa forma, sugerem estudos sobre as prováveis dificuldades e benefícios das PD no meio das atividades físicas de modo geral, acreditando que as informações ali geradas seriam valiosas. Imergindo no universo das LAM, é afirmado por Kelland (2012) que a prática de tais atividades pode ser uma ferramenta de colaboração significativa ajudando PD em aspectos físicos, cognitivos e mesmo espirituais. No entanto, é de se observar a pequena escala de trabalhos que citam especificamente o uso de LAM para as PD, seus benefícios, conquistas e dificuldades ao decorrer da história (Toffoli, 2012).

Assim, no caminho de convergência dos aforismos relatados, este artigo objetivou aprofundar-se nessa temática, pesquisando como as LAM foram ou estão sendo adaptadas para a inclusão das PD dando aqui maior ênfase à sua vertente desportivo-competitiva em âmbito mundial e mais especificamente no Brasil.

\section{Metodologia}

Esta pesquisa classifica-se como de qualidade analítica histórica (Thomas, Nelson \& Silverman, 2007). Fez-se uso da revisão narrativa de literatura buscando dados históricos sobre a temática da deficiência e posteriormente convergindo a atenção ao universo das atividades físicas e práticas desportivas adaptadas destacando as LAM. O levantamento de material bibliográfico abrangeu livros e capítulos de livro (alguns especializados e já outros considerados clássicos), pesquisas acadêmicas de licenciatura e stricto sensu, artigos de conceituados periódicos da área do desporto em geral e especializados em LAM e importantes documentos que ajudam a nortear a área do desporto (direta ou indiretamente).

Esclarece-se desde já que adotou-se a nomenclatura LAM neste estudo, pois a mesma é a utilizada nos Parâmetros Curriculares Nacionais (Brasil, 1998), não sendo aqui o palco de discussão 
e aprofundamento sobre as diferenciações entre os termos "lutas" e "artes marciais". Outrossim, faz-se uso da expressão "deficiente", pois a mesma é a utilizada no Relatório Mundial sobre a Deficiência (OMS, 2012). Para delimitação da pesquisa, foram elencadas sete LAM. Esclarece-se que a esgrima, o judo, o karate, o boxe e o taekwondo foram selecionados por serem LAM olímpicas, o kung-fu por pleitear ser uma LAM olímpica e a capoeira por ser uma LAM brasileira maciçamente utilizada como ferramenta inclusiva no país. Espera-se que este estudo possa colaborar com as comunidades deficiente, marcial, esportiva e acadêmica, trazendo à luz as peculiaridades das LAM em benefício da PD.

\section{Mudanças históricas da pessoa com deficiência na sociedade}

Atualmente, a sociedade humana passa por mudanças importantes de pensamentos sobre suas posturas práticas e hábitos do dia-a-dia. Uma tradicional reflexão na clássica e milenar obra oriental "Tao Te King" de autoria de Lao Tsè (2001) explica que a cultura humana é uma "arte viva", portanto ela deve sim estar em constante transformação. Tal fato pode ser também direcionado para que todos possam adaptar-se às adversidades superando assim as dificuldades que venham a surgir em qualquer momento em prol de uma harmonia maior de toda humanidade sem a exclusão de qualquer ser.

Sob o prisma socioeducacional, a busca da inclusão para PD nem sempre aconteceu. Porém, após séculos de mudanças faz-se hoje um exemplo marcante do pensamento filosófico oriental elevado anteriormente. É importante destacar que o âmbito socioeducacional engloba funções diversas, como: o aprimoramento intelectual para fins profissionais, a promoção da saúde e reabilitação física, interações sociais com a comunidade, possibilidades de práticas esportivas e lúdicas para o lazer e o alívio do estresse cotidiano com fins psicoterapêuticos.

Tanto no trabalho de Lowenfeld (1973) quanto no de Kirk e Gallagher (1979) são pontuados quatro importantes períodos históricos relacionados diretamente com as diferentes posturas adotadas para com esse público. Posteriormente, Marques, Castro e Silva (2001) ampliam essa pesquisa destacando um quinto e último período bem mais recente e próximo aos dias atuais, a saber:

- 1‥ Período - separação: Este período remete desde as antigas sociedades primitivas até o início da Idade Média, quando as PD eram vistas como influenciadas de forma mágica ou mesmo religiosa por espíritos de origem demoníaca.

- 2․ Período - proteção: Ao final da Idade Média, este período ganha embasamento, pois o sentimento público passou de medo e horror para pena e caridade. Através de ordens religiosas, foram criadas casas de abrigo como asilos e hospícios para assistir e auxiliar as PD. Tais auxílios eram majoritariamente efetuados não pelo desejo de auxiliar o próximo e os necessitados, mas sim, de que fazendo isso poderiam garantir seu lugar no céu no pósmorte (visão religiosa).

- 3‥ Período - emancipação: 0 estudo do ser humano na Era Renascentista faz com que este período surja na Europa. Algumas PD começam a serem instruídos e buscam seus lugares no mercado de trabalho, mesmo que de forma modesta. Só no fim do século XVIII, já durante a Era Iluminista na Revolução Francesa, as questões das PD começaram a ser analisadas de forma racional e científica. Em 1801, tem-se o primeiro apontamento histórico oficial da chamada educação especial inclusiva (direcionada à PD) quando Stard tenta educar Victor (uma PD também conhecido como o selvagem de Avignon). No fim do século XIX, a educação especial inclusiva passa a ser ministrada em colégios especiais no molde de internato, sendo cada uma das PD direcionadas para o local que atendesse a característica específica, seja ela visual, auditiva, mental, motora ou autista. É citado também que foi no fim deste período que apareceram os primeiros defensores do sistema educacional integrado no qual os educandos teriam contato parcial ou mesmo total com outras classes regulares, objetivando a integração escolar, familiar e social.

- 4o. Período - integração: No período temporal de mudança entre os séculos XIX e XX, a busca pela integração das PD tenta igualar as condições de aprendizagem no foco sociocultural. A 
busca teve como objetivo criar condições de vida próximas ou mesmo semelhantes as dos outros membros da sociedade ditos como "normais".

- 5․ Período - inclusão: Já na Idade Contemporânea, as visões educacionais reflexivas sobre a realidade das PD fazem com que diversas leis, manifestos, conferências e declarações surjam sendo muitas delas através de acordos internacionais. A busca pela dignidade, direitos iguais e a garantia de integração social geral passam a ser marcantes na sociedade de forma global.

Após analisar os cinco períodos anteriormente relatados, observa-se uma rigorosa transformação em toda a paisagem social em escala mundial e consequentemente, sensíveis mudanças nos princípios políticos, educacionais e culturais globais. Para além disso, pode-se elevar aqui talvez um aumento não só de autoconsciência do corpo humano, mas também de humanidade (Novaes, 2006). Destaca-se ainda que uma das manifestações humanas que destacou-se notadamente ao decorrer dos tempos é a atividade física e suas práticas esportivas, que convergem as peculiaridades e idiossincrasias de culturas e épocas, como sabiamente é exposto por Tubino (1993, p.12): “a história do desporto é íntima da cultura humana, pois por meio dela se compreendem épocas e povos, já que certo período histórico tem o seu esporte e a essência de cada povo nele se reflete". Hoje, é possível afirmar que atividades físicas e práticas esportivas ganham muito mais funções e objetivos do que em outrora, sendo utilizadas e adaptadas para públicos diversos na competição, no lazer, na socialização, na saúde, na educação e na inclusão (Tubino, Tubino, \& Garrido, 2007).

\section{A educação física escolar na infância das pessoas com deficiência}

Já é considero um axioma que a busca de uma atividade física frequente e equilibrada (principalmente desde a infância) promove benefícios relevantes aos seus praticantes em seu cotidiano (Seron, et al., 2015). No caso das PD é destacado por Almeida e Silva (2009) que tais práticas auxiliam sensivelmente na superação das restrições estruturais (altura, peso, massa muscular e afins), funcionais (interações socioculturais), ambientais (tipos de piso e parede, obstáculos, gravidade, ônibus sem rampa de acesso, poluição sonora e afins) e de tarefa (metas, regras e equipamentos que utilizar-se-ão nas práticas) dos adeptos. É enaltecido por Ribeiro (2009) que a atividade física já na infância ganha brilho ainda maior quando elevado nas aulas de educação física escolar, podendo gerar uma importante desenvolvimento ou mesmo reabilitação cognitiva e psicomotora dos praticantes para além de aspectos inclusivos sociais e afetivos. A pesquisa de Fernandes, Dalquano e Oliveira (2003) concluiu que a recreação proporciona aos alunos uma maior interação não só entre eles, mas também com o docente, pontuando o aumento da participação do grupo com mais entusiasmo e desenvoltura nas atividades ao longo do ano letivo. Indo ao encontro desse pensamento, Boccardi (2003) relata que o brincar foi o caminho e peça-chave para o sucesso de interação e inclusão das crianças especiais, pois além de satisfazer os desejos lúdicos infantis, gerou também minimização da resistência das outras crianças para com as mesmas.

Todavia, Alves e Duarte (2013) apresentam o outro lado da moeda em seu artigo, trazendo à luz a grande dificuldade de interação social de um aluno com Síndrome de Down (SD) com uma classe de jovens tidos como "normais". Ainda destacam tópicos importantíssimos, como um docente não preparado pode piorar a situação do educando.

A inclusão do aluno com SD durante as aulas de educação física esbarra em dificuldades severas para promover a sua participação social junto à turma. Os resultados aqui descritos demonstram um prejuízo por parte do mesmo em estruturar relações sociais com seus pares durante as aulas de educação física. Este manteve durante todo o ano o status de ignorado, indicando sua baixa visibilidade e empatia junto aos seus colegas de classe. Apesar do seu status de ignorado, o aluno conseguiu estruturar uma relação de reciprocidade durante o ano letivo, bem como relações de troca com um reduzido número de colegas (Alves \& Duarte, 2013, p.1107).

Como uma forma de adaptação para ambos os alunos, Silva e Silva (2005) afirmam que a inclusão deve ser o princípio educacional das atividades competitivas, fazendo com que as PD participem 
ativamente do processo sempre que possível, gerando consequentemente a cooperação natural das partes para com seus pares - um passo importante para superar a exclusão nas escolas. Ainda nesse prisma, afirmam também que de certa forma, a vida estudantil cotidiana, como no ensino e no aprendizado, são sim uma espécie de jogo onde deve sempre andar ladeada com a cooperação mútua. Este pensamento aproxima-se imenso do chamado Processo Civilizador de Norbert Elias (1994), onde é defendido que a humanidade precisa de atitudes práticas que sirvam como amarras e freios para as manifestações de violência que ocorrem na sociedade. Esclarece-se que o preconceito é uma das materializações do fenômeno da violência sob um olhar sócio antropológico (Mocarzel, Murad, Ferreira \& Silva, 2012). Indo além e aprofundando-se na perspectiva civilizadora, o esporte também é destacado e defendido por Mocarzel e Murad (2012) afirmando que o mesmo não só pode, mas deve sempre ser utilizado como uma ferramenta educativa e humanizada, algo já preconizado por Tani (2002) quando alertado sobre a supervalorização do esporte de rendimento, deixando abandonadas outras vertentes fundamentais do esporte, como suas manifestações culturais, educativas, inclusivas, dentre outras. É nessa guisa que na pesquisa de Pereira, Osborne, Pereira e Cabral (2013) é exposto o esporte de alto rendimento como grande contribuidor na inclusão social de todos os seus entrevistados, tendo colaborado com seus objetivos e ideais pessoais. Mais; sugerem que a prática esportiva seja inserida em todas as instituições para PD (ou de ensino especial).

\section{As lutas / artes marciais no universo das pessoas com deficiência no brasil e no mundo}

Junto às práticas esportivas que misturam-se à história humana tem-se as LAM, que ao decorrer dos tempos, integrou o perfil cultural de povos e nações em todos os pontos do globo (Gomes, Morato, Duarte, \& Almeida, 2010; Acevedo, Gutiérrez-García, \& Cheung, 2011; Mocarzel \& Columá, 2015). Hoje, diversos países têm as LAM como práticas marcantes de suas culturas. 0 Brasil integra essa lista sendo um massivo adepto de tais práticas, tornando-as muito populares no país. Contraditoriamente, as LAM no Brasil são pouquíssimo difundidas nas aulas de educação física escolar, mesmo tendo suas práticas recomendadas pelos Parâmetros Curriculares Nacionais (Brasil, 1998) e ainda fazendo parte da cultura esportiva nacional (Mocarzel \& Murad, 2013). Esse fato vem inclusive sendo alvo de reflexões e pesquisas que abordam tal questão (Nascimento \& Almeida, 2007). Majoritariamente, as práticas de LAM no Brasil ocorrem em "centros de ensino não acadêmicos", ou seja, tradicionalmente não são ensinados em escolas e universidades, mas sim em associações esportivas, ginásios esportivos e núcleos de treinamento marcial.

No hemisfério norte do planeta é mais comum observar as LAM inseridas nos colégios e universidades. Porém, esse fator fica em exponencial quando os olhares convertem-se para o continente asiático. É de ressaltar-se que pelo elevado número de atividades, jogos e desportos de características marciais no Oriente, nota-se facilmente a importância singular e profunda que as sociedades orientais acolhem essa questão - bem mais que no Ocidente (Almeida, Corbett \& Gutierrez, 2009).

Na sociedade oriental, as LAM também são difundidas nas escolas dentro das aulas de educação física, fazendo com que as valências trabalhadas, os valores morais e disciplinas desenvolvidas possam desabrochar já na idade infantil, tendo a supervisão de profissionais graduados e qualificados. Na China, treinos de diversos estilos de kung-fu (ou wushu) fazem parte integrante oficialmente do conteúdo escolar desde 1925 (Lima, 2000), embora esses estilos já fossem difundidos anteriormente a essa data pelo kung-fu ser parte integrante da cultura chinesa. No Japão existem aulas de judo para os universitários do país de forma a difundir a cultura nipônica e também ser uma ação de promoção da saúde para a comunidade acadêmica que passam por longos períodos de estudo, normalmente conflitando com seus horários de atividade física e lazer (Mocarzel \& Columá, 2015).

Indiscutivelmente, uma das facetas da educação física desde idades escolares seria a descoberta de possíveis futuros talentos do esporte, buscando assim vindouros ídolos e destaques para a sociedade. No entanto, a busca das PD não faz-se a mesma, principalmente no Brasil. 0 esporte é muito utilizado para o desenvolvimento e aprimoramento das capacidades psicomotoras dos praticantes, atendendo primordialmente caracteres de promoção da saúde. Essa colocação vem 
somar ao pensamento de Souza Sobrinho (2006) observando também a individualidade e especificidade de cada situação.

\begin{abstract}
Considerando-se estar já por algumas vezes, mencionada a pobreza de experiência motoras, sociais, emocionais e esportivas em crianças e jovens com deficiência, somos de opinião que, em muitos casos, se deveria promover uma estimulação psicomotora para assegurar uma base de desenvolvimento, para depois se dar ênfase à iniciação esportiva no ambiente escolar. Por outro lado, deve-se reconhecer que muitas crianças e jovens com deficiência já apresentam plenas de prática esportiva, quando iniciam o processo de escolarização. Ou seja, cada caso é um caso. (Souza Sobrinho, 2006, p.47)
\end{abstract}

Dentro das escolas brasileiras, as PD conseguiram maior inserção e participação através das aulas de educação física inclusiva que, paulatinamente, têm obtido resultados significantes (Ferreira, 2011). Dessa forma, cada vez mais as PD integram o público praticante de atividades físicas e esportes, incluindo aqui as LAM. Consequentemente, muitas LAM têm buscado adaptações desportivas para a inclusão das PD em suas práticas e competições, criando categorias exclusivas com regras adaptadas para que todos tenham possibilidades iguais de vitória, seguindo o princípio filosófico desportivo do Agon, que prima pelo espírito competitivo desde que os competidores estejam em igualdade (Retondar, 2013). Tal princípio educacional é também um dos pensamentos que norteiam o espírito olímpico (Comitê Olímpico Internacional [COI], 2001).

A grandiosidade da estética, vertente axiológica inerente ao esporte, ganha ainda mais elevadas proporções quando expressada através da superação das adversidades por um paratleta com um corpo tido muitas vezes por olhares leigos como "deficiente" (Lacerda, 2007). É no tocante dessa vertente estética filosófica que em 1960, o COI realizou em Roma (Itália) a primeira edição dos Jogos Paralímpicos ${ }^{1}$ (JP), estabelecendo-se a partir de então como o maior evento esportivo para PD no mundo. 0 mesmo ocorre periodicamente a cada quatro anos em diferentes locais pelo mundo junto com os Jogos Olímpicos (JO). Desde a primeira edição dos JP a Esgrima integra o programa desportivo (Boguszewski \& Torzewska, 2011). Adaptada para praticantes com dificuldades de locomoção, os paratletas competem em cadeiras de rodas com suas rodas fixas ao chão; se um dos esgrimistas mover a cadeira, o combate é interrompido. Mantendo os padrões tradicionais, há duelos de florete, espada e sabre. Em cada prova, há proteções específicas para os competidores e para as cadeiras. Há também regras específicas para a pontuação ser validada. No Brasil, a esgrima para cadeirantes começa a ganhar forma competitiva inclusive internacionalmente. Nos JP de 2012 (Londres, Reino Unido), o Brasil ganhou pela primeira vez uma medalha na modalidade. 0 gaúcho Jovane Guissone sagrou-se campeão paralímpico derrotando na final de forma emocionante seu adversário Chik Sum Tam, de Hong Kong. 0 combate terminou em 15 a 14 para o brasileiro. Porém, nos JP de 2016 (Rio de Janeiro, Brasil) o Brasil não conquistou medalhas nesse esporte. Isso demonstra que o país ainda precisa se consolidar nos trabalhos de base para destacar-se futuramente como uma referência.

Já o judo fez sua estreia no evento em 1988 (Seul, Coréia do Sul); na época, só participaram homens com deficiências visuais. Esse fato repetiu-se em 1992 (Barcelona, Espanha), 1996 (Atlanta, Estados Unidos da América) e 2000 (Sydney, Austrália). Porém, em 2004 (Atenas, Grécia) ocorreu o ingresso feminino nos tatames paralímpicos. A entidade responsável pelo esporte é a Federação Internacional de Esportes para Cegos, fundada em Paris (França), em 1981. O Brasil é hoje uma das maiores potências mundiais nessa prática adaptada. Seus resultados são extremamente expressivos desde os o início do judo nos JP de 1988.

Outro fato de méritos e aplausos é o evento "Judo for all" (Judo para todos). Um evento mundial que conglomera paratletas de judo com diferentes deficiências, já que nos JP apenas as PD visual podem participar. No "Judo for all" competem pessoas com SD, Síndrome do x frágil, dentre outros (Confederação Brasileira de Judo [CBJ], 2014a). Importante dizer, o Brasil também é uma potência mundial nessa modalidade esportiva, tendo ainda sido relatado pela CBJ (2014b) a

\footnotetext{
1 Houve grande confusão no Brasil sobre qual deveria ser a nomenclatura adotada para o Comitê Olímpico responsável pelas competições desportivas às PD. Após inúmeros debates sobre o assunto, o governo brasileiro interveio e determinou (de forma ainda extremamente polêmica) que a nomenclatura a ser adotada não seria mais "paraolímpico" tão pouco "para-olímpico", mas sim "paralímpico" (Rodrigues, 2012).
} 
primeira participação de uma mulher na equipe nacional em um torneio na Itália em maio de 2014. Nos JP de 2016 o Brasil conquistou quatro medalhas de prata (2‥ lugar), demonstrando assim sua alta capacidade competitiva como equipe em âmbito mundial.

Observando agora outra LAM de natureza nipônica, o karate tem buscado sua adaptação para PD. 0 trabalho de Barnfield (2004) aborda um programa bem sucedido para jovens deficientes auditivos no Canadá fazendo uso do karate. Todavia, a adaptação para pessoas de cadeiras de rodas surge com maiores proporções e destaca-se que após estudos recentes, foram observadas melhorias tanto de caráter quantitativo quanto qualitativo.

Os voluntários obtiveram uma queda de 9,59\% no tempo e de 14,28\% na frequência cardíaca do primeiro para o terceiro teste ziguezague de agilidade. Além disso, ao verificar a satisfação com a vida atual comparada com a do início das aulas de Karatê, observou-se que os sujeito passaram de "mais ou menos" satisfeito para "muito satisfeito" nos aspectos saúde mental, saúde física e capacidade física (Rosa, Rodrigues \& Freitas, 2009, p.1).

Ainda é reforçado pelos mesmos autores que tal prática adaptada poderia ser muito útil para iniciação às atividades físicas ao referido público-alvo. Complementando esse pensamento, pondera-se ainda que a busca do karate em ter uma prática competitiva adaptada para PD colaborou (mesmo que indiretamente) com sua inclusão no programa do COI para fazer parte oficialmente dos JO de Tóquio em 2020. Este fato é algo perseguido pelo karate já há décadas, mas por questões internas e políticas (mesmo dentro do COI), sempre teve diversos empecilhos (Figueiredo, 2006). Todavia, sua inclusão nos JP ainda não ocorreu. Não foram encontrados mais relatos ou estudos sobre outras possíveis adaptações para esta prática.

Outra LAM que tem buscado firmemente suas adaptações para incluir as PD no universo desportivo marcial é o kung-fu (ou wushu), uma prática chinesa das mais antigas que se têm registros no mundo (Lima, 2000; Figueiredo, 2006; Antunes, 2013; Mocarzel \& Columá, 2015).

Vem-se tentando inserir o kung-fu nos JO desde 1936, quando participou pela primeira vez como esporte de demonstração em Berlim (Alemanha). Essa movimentação ganhou força com a fundação da República Popular da China em 1949, havendo pouco tempo depois diversas reuniões para buscarem o formato de adaptação uniforme do kung-fu em âmbito desportivo-competitivo, o que hoje é chamado de wushu moderno (Acevedo, et al., 2011). Após isso, os esforços para inserção de tal prática em megaeventos estão sendo trabalhados progressivamente. Esta LAM já conseguiu seu ingresso nos Jogos Asiáticos em 1990 (Apolloni, 2004; Tubino, et al., 2007). Nos J0 de 2008 em Pequim (China) foi pela segunda vez um esporte de demonstração contando com a participação de três brasileiros (Mocarzel, Murad \& Capinussú, 2013). Porém, quando observado num prisma mundial e globalizado, as adaptações para a vertente esportiva do kung-fu não são uniformes. Muitos países ainda não realizaram ou mesmo criaram adaptações aos paratletas, colocando esta LAM ainda um pouco afastada do universo dos JP de forma padronizada e organizada.

No Brasil, a Confederação Brasileira de Kung Fu/Wushu (CBKW) desenvolveu nos últimos anos categorias competitivas tanto em formas (demonstrações de coreografias marciais) quanto combate (lutas desportivizadas) (Antunes, 2013). Mesmo contando ainda com poucos inscritos, pode-se reconhecer que foi dado início aos trabalhos para inclusão das PD em tal esporte efetivamente. Na divisão de combate, o Campeonato Brasileiro de 2012 em Fortaleza/CE promoveu a categoria para PD visual na categoria de Shuai Jiao, prática de agarro, quedas e arremesso do kung-fu que aproxima-se de certo modo à prática adaptada paralímpica do judo para PD visual. Já na divisão de formas, o Campeonato Brasileiro de 2013 em Valinhos/SP realizou categoria de estilos tradicionais externos e internos para PD mental e de estilos tradicionais internos para cadeirantes.

Outra prática já milenar que tem em sua vertente desportiva uma ampla difusão mundial é o boxe. Sua popularidade é extensa em diversos países do mundo há décadas, como em Cuba, México, os países da chamada antiga Cortina de Ferro e em especial nos Estados Unidos da América e Inglaterra. E exatamente nesses dois últimos países, há relatos orais de adeptos e simpatizantes do boxe que vem crescendo um movimento de adaptação para pugilistas cadeirantes. Esta adaptação dá ares de também estar sendo estimulada (mesmo que informalmente) por militares reformados, 
muitos feridos em combate. Dessa forma, a busca da inserção de PD de locomoção no boxe começou a ganhar a mídia e já existem algumas competições amadoras de forma nucleada e ainda muito pulverizada nesses dois países.

Muito embora o boxe seja bem difundido em diversos países, faça uso de pouco material para prática, tenha regras com fácil entendimento do público e ainda seja uma das práticas olímpicas mais antigas que se tem registro (Mocarzel \& Columá, 2015), não há qualquer indicação do COI em buscar inserir tal prática adaptada nos JP para PD até o momento. Também não foram encontrados quaisquer relatos de eventos ou mesmo núcleos de treinamento de boxe adaptado no Brasil.

Já o taekwondo, LAM olímpica coreana, iniciou em 2005 sérias movimentações administrativas e organizacionais através da criação de um comitê específico da WTF (World Taekwondo Federation), órgão que rege a prática sob a vertente desportiva olímpica (Figueiredo, 2006), para a criação de uma adaptação da mesma visando o paradesporto às PD. Segundo a WTF (2016), seu primeiro evento de âmbito mundial foi em 2009 em Baku (Azerbaijão). Desde então, o taekwondo expandiu seus horizontes constantemente, trabalhando com amputados, cadeirantes e PD mental; recebendo inclusive em 16 de outubro de 2013 aplausos do Comitê Paralímpico Internacional (CPI). Em 2014, a WTF oficializou junto ao CPI o desejo de incluir o chamado até então Para-taekwondo nos JP de Tóquio (Japão), a ser realizado em 2020. Por fim, no dia 31 de janeiro de 2015, o Para-taekwondo foi incluído oficialmente no programa paralímpico e integrará o corpo de atividades nos JP de Tóquio (Comitê Paralímpico Brasileiro [CPB], 2015). Agora, essa prática é convergida para pessoas sem os membros superiores por amputação ou má formação e golpes na cabeça não são permitidos (Patatas, 2012).

O Brasil tem bom destaque no cenário internacional do taekwondo nos últimos vinte anos, possuindo medalhas em competições panamericanas, mundiais e olímpicas. Por outro lado, os próprios mestres responsáveis pela difusão do taekwondo competitivo no país afirmam saber pouquíssimo ou mesmo desconhecerem a prática do Para-taekwondo no Brasil (Patatas, 2012).

Posicionando-se mais afastada do universo competitivo (incluindo os JO e JP), a capoeira, uma das LAM que menos enfatiza e vivifica a competição, é ainda sim uma forte aliada do processo inclusivo principalmente sob a perspectiva sociocultural. É uma maciça representante do conceito de identidade (Murad, 2007) do Brasil e hoje difundida mundialmente (Melo \& Barreira, 2015). Utiliza de maneira singular elementos estéticos amplamente perceptíveis (Castro Júnior, 2004) e estimula a ludicidade, a musicalidade e o trabalho dinâmico em grupo - como as rodas e as músicas cantadas e tocadas em conjunto por todos - para criar um universo de união e inclusão do grupo (Reis Filho \& Schuller, 2010). Este último ponto é uma das bases da solidariedade, tópico bastante elevado no resultado da pesquisa de Mello, dos Santos, Rodrigues e Santos (2014).

Tais visões de âmbito não só cultural, mas também terapêutico e de reabilitação da Capoeira, já são aceitos popularmente, embora aparentemente não tão explorados academicamente. No sul do Brasil, a prática desta LAM já é inserida nas escolas municipais de Porto Alegre/RS, incluindo duas escolas especiais ou exclusivas para PD (Costa, 2010). Encontrou-se também atividades para PD intelectual em Santa Maria/RS fazendo uso da capoeira focando o desenvolvimento coordenativo, a reabilitação psicomotora e a socialização (Palma, Manta, Lehnhard \& Matthes, 2012). Por ser uma prática de trabalho corporal extensiva, as pesquisas de Brito (2008) apontam a suposta melhora de praticantes de Capoeira sendo estes PD em seus níveis de coordenação motora. Matos e Menezes (2012) afirmam que o equilíbrio de PD visual era praticamente idêntico sendo praticantes de Capoeira ou não, muito embora os capoeiristas tenham obtido melhor resultados de desempenho em testes aplicados.

\section{Considerações finais}

Através desta pesquisa foi possível observar que a riqueza e a diversidade cultural trazem colaborações significativas sob o prisma educacional nas LAM, facilitando a inserção das PD na sociedade e no universo da atividade física. Tais colocações dão possibilidades de pontuar que essas práticas possuem valia no uso do combate da exclusão às PD. Já sob o foco da promoção da saúde, a 
visão holística das LAM trazida por Lima (2000) busca o aprimoramento e aperfeiçoamento de diversas áreas, perfazendo assim aspectos afetivos, cognitivos e psicomotores. Sociologicamente, o uso das LAM vai para além das visões de autodefesa e preparo físico. De fato, as mesmas ainda podem colaborar com o lúdico, com a estética, com a transmissão de valores educacionais e com o sentimento agonístico competitivo do ser humano (Mocarzel, 2011; Coelho, Kreft, \& Lacerda, 2013). Tem-se em mente que tais predicados das LAM vão ao encontro das colocações de Bento e Bento (2014, p.51) que esclarecem sobre o desporto: "Essencialmente pertence ao domínio do simbólico e 'artístico': cumpre objetivos educativos, sociais, filosóficos e culturais, éticos, estéticos e morais. Serve o processo civilizador, isto é, visa melhorar o índice de civilização".

Vê-se a importância de haver maior ação das entidades que comandam e regem as LAM para buscarem possíveis adaptações às $\mathrm{PD}$, independentemente do objetivo ser no âmbito competitivo ou apenas para foro íntimo. Destaca-se também que muitas práticas ainda nem iniciaram suas adaptações e outras apenas de forma pontual e não globalizada. Faz-se mais que necessário compreender as possíveis dificuldades e reais necessidades das PD, e mais, fomentar e desafiar (dentro de parâmetros possíveis) seus limites em busca do desenvolvimento físico, mental e social. 0 meio acadêmico pode e deve trazer suas contribuições para tal causa, afastando-se assim da prática citada por Drigo, Souza Neto, Cesana, Tojal e Gomes (2011, p.49) que pontua, por exemplo, que o "judo brasileiro distancia-se do modelo de formação acadêmica, mantendo-se atrelado às tradições do saber-fazer".

Recomendam-se mais estudos sobre as temáticas de inclusão de PD através das atividades físicas, do paradesporto e das LAM, principalmente as que não possuem inserção olímpica e paralímpica, pois poucos estudos dessas práticas (com alguma exceção do kung-fu e da capoeira) foram encontrados, pontuando seus aspectos inclusivos, como a reabilitação motora através da LAM russa sambo (Bulantsov \& Tabakov, 2011) e a harmonização de picos de ansiedade por meio da LAM jiu-jítsu (Almeida \& Silva, 2009).

Nota-se que as LAM podem apresentar um caminho de inclusão e elevação dos praticantes, indo para muito além das deficiências e focando-se sim nas eficiências. Dentro dessa perspectiva, apresenta-se aqui um belíssimo pensamento estético de Sócrates reproduzido por seus discípulos Platão e Xenofonte após sua morte: "Nenhum cidadão tem o direito de ser um amador em matéria de treinamento físico. Que desgraça é para o homem envelhecer sem nunca ver a beleza e a força do que o seu corpo é capaz".

\section{References}

Acevedo, W., Gutiérrez-García, C., \& Cheung, M. (2011). Breve história do Kung Fu (F. Delgado, Trad.). São Paulo: Madras.

Almeida, M. A. B., Corbett, C. A., \& Gutierrez, G. L. (2009). 0 processo civilizatório da marcialidade e a figura feminina. Movimento \& Percepção, 10(14), 164-179.

Almeida, M. O., \& Silva, R. F. (2009). Atividade motora adaptada e desenvolvimento motor: possibilidades através das artes marciais para deficientes visuais. Movimento \& Percepção, 10(14), 222-239.

Alves, M., \& Duarte, E. (2013). Inclusão social e o aluno com síndrome de down: um estudo de caso nas aulas de educação física. Pensar a Prática, 16(4), 1098-1111.

Andrade, A., \& Almeida, M. (2012). Análise documental das políticas públicas de incentivo as práticas físico-esportivas e de lazer para as pessoas com deficiência no Brasil. Conexões, 10(3), 42-60.

Antunes, M. M. (2013). As artes marciais chinesas para pessoas com deficiência: contextos, dilemas e possibilidades. Tese de Doutoramento em Educação Física, Universidade Estadual de Campinas, Campinas, SP, Brasil.

Apolloni, R. W. (2004). "Shaolin à brasileira": estudo sobre a presença e a transformação de elementos religiosos orientais no Kung-Fu praticado no Brasil. Dissertação de Mestrado em Ciências da Religião, Pontifícia Universidade Católica, São Paulo, SP, Brasil.

Azevedo, P. H., \& Barros, J. D. F. (2004). O nível de participação do Estado na gestão do esporte brasileiro como fator de inclusão social de pessoas portadoras de deficiência. Revista Brasileira de Ciência \& Movimento, 12(1), 77-84. 
Barnfield, A. (2004). Traditional martial arts with a non-traditional population: Teaching the Deaf. Journal of Asian Martial Arts, 13(4), 16-27.

Beltrame, A. L. N., \& Sampaio, T. M. V. (2015). Atendimento especializado em esporte adaptado: discutindo a iniciação esportiva sob a ótica da inclusão. Revista da Educação Física/UEM, 26(3), 377-388.

Bento, J. O., \& Bento, H. C. (2014). Desporto e valores: uma aliança natural carecida de renovação. 42nd Conference of the IAPS-International Association for the Philosophy of Sport \& 1st Conference of the ALFID-Asociación Latina de Filosofia del Deporte, Natal, Brasil, 3-6 setembro de 2014.

Boccardi, D. (2003). Programa de interação motora lúdica inclusiva: análise motora e social de casos específicos de deficiência mental, síndrome do x-frágil, síndrome de down e criança típica. Dissertação de Mestrado em Ciências do Movimento Humano, Universidade Federal do Rio Grande do Sul, Porto Alegre, RS, Brasil.

Boguszewski, D.; Torzewska, P. (2011). Martial arts as methods of physical rehabilitation for disabled people. Journal of Combat Sports and Martial Arts, 2(1), 1-6.

Brasil - Secretaria de Educação Fundamental. (1998). Parâmetros curriculares nacionais: educação física / Secretaria de educação fundamental. MEC / SEF.

Brito, A. C. (2008). Capoeira, um contributo para a coordenação motora em indivíduos com síndrome de down. Dissertação de Mestrado em Ciências do Desporto, Universidade do Porto, Porto, Portugal.

Bulantsov, A., \& Tabakov, S. (2011). Motor skills reliability of the throws technique of the young SAMBO players. Journal of Combat Sports and Martial Arts, 2(2), 79-82.

Castro Júnior, L. V. (2008). Capoeira Angola: olhares e toques cruzados entre historicidade e ancestralidade. Revista Brasileira de Ciências do Esporte, 25(2), 143-158.

Coelho, R., Kreft, L., \& Lacerda, T. (2013). Elementos para a compreensão da estética do Taekwondo. Movimento, 19(3), 295-314.

Comitê Olímpico Internacional. (2001). Carta Olímpica. Lausanne: Comitê Olímpico Internacional.

Comitê Paralímpico Brasileiro. (2015). Recuperado em 31 Mar., 2015, de http://www.cpb.org.br/comite-paralimpico-internacional-anuncia-programa-final-dosjogos-de-toquio-2020/

Confederação Brasileira de Judo. (2014a). Recuperado em 22 Ago., 2014, de http://www.cbj.com.br/noticias/3106/medalha-para-o-brasil-em-importante-etapa-dojudo-for-all.html/imprimir

Confederação Brasileira de Judo. (2014b). Recuperado em 22 Ago., 2014, de http://www.cbj.com.br/noticias/3893/equipe-brasileira-de-\%E2\%80\%9Cjudo-paratodos\%E2\%80\%9D-campea-na-italia-retorna-ao-brasil.html

Conselho da Europa. (1992). Carta Europeia do Desporto. Rhodes: 7a Conferência dos Ministros Europeus.

Costa, A. K. (2010). A prática da Capoeira nas escolas especiais da rede municipal de ensino de Porto Alegre, Rio grande do Sul. Monografia de Licenciatura de Educação Física, Universidade Federal do Rio Grande do Sul, Porto Alegre, RS, Brasil.

Drigo, A.J., Souza Neto, S., Cesana, J., \& Tojal, J.B.A. Gomes. (2011). Artes marciais, formação profissional e escolas de ofício: Análise documental do judô brasileiro. Motricidade, 7(4), 4962.

Dunning, E. \& Elias, N. (1994). Sport et civilisation: la violence maîtrisée. Paris: Fayard.

Elias, N. (1994). O processo civilizador: uma história dos costumes. Rio de Janeiro: Jorge Zahar Editores.

Fédération Internationale d'Education Physique - FIEP. (2000). Manifesto Mundial de Educação Física FIEP 2000. Foz do Iguaçu: FIEP.

Fernandes, C. A. M., Dalquano, A. B., \& Oliveira, R. M. (2003). A influência de atividades recreativas no comportamento social de portadores de deficiência mental. In Anais do XIII Congresso Brasileiro do Ciências do Esporte. Caxambu: Colégio Brasileiro de Ciências do Esporte.

Ferreira, E. L. (Org.). (2011). Atividades físicas inclusivas para pessoas com deficiência. 1. Mogi das Cruzes: Confederação Brasileira de Dança em Cadeira de Rodas. 
Figueiredo, A. A. A. (2006). A institucionalização do Karaté - os modelos institucionais do Karaté em Portugal. Tese de Doutorado de Motricidade Humana, Faculdade de Motricidade Humana, Lisboa, Portugal.

Garcia, M. (2005). Des pratiques physiques et artistiques dans des logiques de socialisation scolaire: hip-hop, cirque et capoeira à l'école. In M. Falcoz \& M. Koebel (Eds.), Intégration par le sport : représentations et réalités (pp. 105-118). Paris : L'Harmattan.

Gasparini, J. (2005). Les contradictions de l'intégration par le sport. In M. Falcoz \& M. Koebel (Eds.), Intégration par le sport : représentations et réalités (pp. 243-260). Paris : L'Harmattan.

Gomes, M., Morato, M., Duarte, E., \& Almeida, J. (2010). Ensino das lutas: dos princípios condicionais aos grupos situacionais. Movimento, 16(2), 207-227.

Kelland, M. (2012). Psicologia, incapacidade física e a aplicação da consciência plena budista nos programas de artes marciais. Revista de Artes Marciales Asiáticas, 4(4), 8-17.

Kirk, S., \& Gallagher, J. (1979). Educating Exceptional Children (3 ed.). Boston: Houghton Mifflin Company.

Kunz, E. (1994). Transformações didático-pedagógicas do esporte. Ijuí: Unijuí.

Lacerda, T. O. (2007). Uma aproximação estética ao corpo desportivo. Revista Portuguesa de Ciências do Desporto, 7(3), 393-398.

Lao, T. (2001). Tao Te King. (5 ed., versão integral e comentários). São Paulo: Attar.

Lever, J. (1983). A loucura do futebol. São Paulo: Record.

Lima, L. M. S. (2000). O Tao da educação - a filosofia oriental na escola ocidental. São Paulo: Ágora.

Lowenfeld, B. (1973). History of the Education of Visually Handicapped Children. In B. Lowenfeld (Ed.), The Visually Handicapped Children in School (pp. 1-25). New York: American Foundation for the Blinds.

Marques, U. M., Castro, J. A., \& Silva, M. A. (2001). Actividade Física Adaptada: uma visão crítica. Revista Portuguesa de Ciências do Desporto, 1(1), 73-79.

Marsiglia, P. M. (2016). Homo Deficiens - tecendo metáforas para os abismos e progressos do eu. Dissertação de Mestrado em Educação, Universidade Nove de Julho, São Paulo, SP, Brasil.

Matos, J. B., \& Menezes, F. S. (2012). Capoeira para deficientes visuais: comparação do equilíbrio entre praticantes e não praticantes de Capoeira. Revista Brasileira de Ciência do Esporte, 34(1), 81-93.

Mello, A., dos Santos, W., Rodrigues, L., \& Santos, R. (2014). O protagonismo de pessoas com deficiência intelectual no processo de ensino-aprendizagem da capoeira. Pensar a Prática, 17(1). 214-227.

Melo, F., \& Barreira, C. R. A. (2015). As fronteiras psicológicas entre violência, luta e brincadeira: as transições fenomenológicas na prática da capoeira. Movimento, 21(1). 125-138.

Mocarzel, R. C. S. (2011). Artes marciais e jovens: violência ou valores educacionais? Um estudo de caso de um estilo de kung-fu. Dissertação de Mestrado em Ciências da Atividade Física, Universidade Salgado de Oliveira, Niterói, RJ, Brasil.

Mocarzel, R. C. S., \& Columá, J. F. (2015). Lutas e Artes Marciais: aspectos educacionais, sociais e lúdicos. Rio de Janeiro: Suam.

Mocarzel, R. C. S., \& Murad, M. (2012). Sobre o Homo Disciplinatus: Uma visão sócio-antropológica do artista marcial. Corpus et Scientia, 8(2), 87-98.

Mocarzel, R. C. S., \& Murad, M. (2013). 0 não uso das lutas na educação física escolar brasileira. In R. Osborne, C. A. F. Silva, \& R. F. Santos. (Org.), Complexidade da educação física escolar (pp. 7080). Rio de Janeiro: Lamparina.

Mocarzel, R. C. S., \& Murad, M, \& Capinussú, J. M. (2013). O Kung-Fu Wushu e os Jogos Olímpicos: história e possibilidades de inserção. Corpus et Scientia, 9(1), 115-125.

Mocarzel, R. C. S., Murad, M., Ferreira, A. S. \& Silva, C. A. F. (2012). Violência e Fair-Play no meio esportivo: o caso do Kung-Fu. Corpus et Scientia, 8(2), 109-124.

Murad, M. (2007). A violência e o futebol: dos estudos clássicos aos dias de hoje. Rio de Janeiro: FGV.

Nascimento, P. R. B., \& Almeida, L. (2008). A tematização das lutas na Educação Física Escolar: restrições e possibilidades. Movimento, 13(3), 91-110.

Novaes, V. S. (2006). O híbrido paraolímpico - ressinificando o corpo do atleta com deficiência a partir de práticas tecnologicamente potencializadas. Dissertação de Mestrado em Ciência do Movimento Humano, Universidade Federal do Rio Grande do Sul, Porto Alegre, RS, Brasil. 
OMS - Organização Mundial da Saúde. (2012). Relatório Mundial sobre a Deficiência (Lexicus Serviços Lingüísticos, Trad.). São Paulo: Governo do Estado de São Paulo - Secretaria dos direitos da pessoa com deficiência.

OMS - Organização Mundial da Saúde. (2016). Disability and rehabilitation. Recuperado em 24 Set., 2016, de http://www.who.int/disabilities/en/

Patatas, J. M. (2012). O Taekwondo como modalidade paradesportiva. Dissertação de Mestrado em Educação Física, Universidade Estadual de Campinas, Campinas, SP, Brasil.

Palma, L. E., Manta, S. W., Lehnhard, G. R., \& Matthes, S. E. R. (2012). Ensino da Capoeira para Pessoas com Deficiência Intelectual. Revista da Sobama, 13(1), 27-30.

Pena, L. G. S., Athayde Costa, A., Campos, L. F. C. C., Gouveia, R. B., Almeida, J. J. G., Duarte, E., Araújo, P. F. \& Gorla, J. I. (2014). O "rugby" em cadeira de rodas no âmbito da universidade: relato de experiência da Universidade Estadual de Campinas. Revista Brasileira de Educação Física e Esporte, 28(4), 661-669.

Pereira, R., Osborne, R., Pereira, A., \& Cabral, S. (2013). A importância do desporto de alto rendimento na inclusão social dos cegos: Um estudo centrado no Instituto Benjamin Constant - Brasil. Motricidade, 9(2), 94-105.

Reis Filho, A. D., \& Schuller, J. A. P. (2010). A capoeira como instrumento pedagógico no aprimoramento da coordenação motora de pessoas com síndrome de down. Pensar a Prática, 13(2), 1-21.

Retondar, J. J. M. (2013). Teoria do Jogo: a dimensão lúdica da existência humana (2ed.). Petrópolis. Vozes.

Ribeiro, S. M. (2009). O esporte adaptado e a inclusão de alunos com deficiências nas aulas de educação física. Tese de Doutorado em Educação, Universidade Metodista de Piracicaba, Piracicaba, SP, Brasil.

Rodrigues, S. (2012, Ago. 14). Sai paraolímpico, entra paralímpico. Revista Veja. Recuperado em 25 Set., 2016, de http://veja.abril.com.br/blog/sobre-palavras/curiosidades-etimologicas/saiparaolimpico-entra-paralimpico/

Rosa, J. P. P., Rodrigues, D. F., \& Freitas, P. S. (2009). A prática do karatê para pessoas em cadeira de rodas. EFDeportes, (133). Recuperado de http://www.efdeportes.com/efd133/karate-parapessoas-em-cadeira-de-rodas.htm

Rosa, V. (2016). Perspetivas e entendimentos dos praticantes portugueses de karaté sobre o conceito de Budô. Revista de Artes Marciales Asiáticas, 10(2), 124-134.

Seron, B. B., Arruda, G. A., \& Greguol, M. (2015). Facilitadores e barreiras percebidas para a prática de atividade física por pessoas com deficiência motora. Revista Brasileira de Ciências do Esporte, 37(3), 214-221.

Silva, C. A. F., \& Silva, H. H. C. (2005). Desafios da Educação Física Inclusiva: integrar ou incluir? Augustus, 10(21), 23-30.

Souza Sobrinho, P. A. (2006). O esporte adaptado e paraolímpico como direito da criança e do adolescente. In A. J. M. Conde, P. A. Souza Sobrinho, \& V. Senatore (Org.). Introdução ao Movimento Paraolímpico: Manual de Orientação para Professores de Educação Física (pp. 2453). Brasília: Comitê Paraolímpico Brasileiro.

Tani, G. (2002). Esporte, educação e qualidade de vida. In W. W. Moreira, \& R. Simões (Orgs.), Esporte como fator de qualidade de vida (pp. 103-115). Piracicaba: UNIMEP.

Thomas, J., Nelson, J., \& Silverman, S. (2007). Métodos de pesquisa em atividade física (5ed.). Porto Alegre: Artmed.

Toffoli, A. (2012). Processo ensino-aprendizagem do Kung Fu em pessoas com deficiência intelectual. In E. Franchini \& F. B. Del Vecchio (Orgs.), Ensino de Lutas: reflexões e propostas de programas (pp. 251-288). São Paulo: Scortecci.

Tubino, M. J. G. (1993). O que é esporte. São Paulo: Brasiliense.

Tubino, M. J. G., Tubino, F. M., \& Garrido, F.A.C. (2007). Dicionário Enciclopédico Tubino do Esporte. Rio de Janeiro: SENAC.

WTF - World Taekwondo Federation. (2016). Para-Taekwondo. Recuperado em 24 Set., 2016, de http://www.worldtaekwondofederation.net/para-taekwondo 


\section{Author's biographical data}

Rafael Carvalho da Silva Mocarzel (Brasil/Portugal), tem dupla nacionalidade: brasileiro e português. É Doutorando em Ciências do Desporto na Universidade do Porto (UP / Portugal) onde agora integra o Centro de Investigação, Formação, Inovação e Intervenção em Desporto da Universidade do Porto (CIFI2D). Possui Mestrado em Ciências da Atividade Física e Licenciatura Plena em Educação Física (UNIVERSO / Brasil). Integrante da Câmara de Lutas e Artes Marciais do Conselho Regional de Educação Física (CREF-1). Presidente de Honra da Associação de Kung-Fu Shaolin de Niterói (AKSN). Ex-diretor da Federação de KungFu do Estado do Rio de Janeiro (FKFERJ). Professor (Faixa Preta) em diversos estilos de Kung-Fu (Garra de Águia, Tai Chi Chuan, Shuai Jiao, Sanda/Sanshou e Wushu Moderno). Já atuou na área de Educação Física Escolar desportiva e competitiva. Foi docente do curso de Bacharel e Licenciatura de Educação Física, ministrante das disciplinas "Luta", "Fundamentos Didático-Metodológicos" e convidado da disciplina "Educação Física, Profissão e Conhecimento" (UNISUAM / Brasil). Hoje estuda as Artes Marciais em suas diversas áreas de atuação, os Jogos Olímpicos (Olimpismo), a Filosofia e Sociologia dos Esportes tão quanto seus valores éticos, morais, estéticos e educacionais. Autor do livro "Lutas e Artes Marciais: aspectos educacionais, sociais e lúdicos" lançado em junho de 2015. Tornou-se o introdutor do estilo e Kung-Fu Garra de Águia em Portugal. Recebeu 16 prêmios e/ou homenagens. Ministrou 49 cursos de curta duração (extensão). Escreveu três capítulos de livros. E-mail: professormocarzel@gmail.com 